\title{
A FITS Scenario-Based Training Program Enhances GPS Pilot Proficiency in the General Aviation Pilot ${ }^{1}$
}

\author{
Wayne A. Dornan, Wendy Beckman, Steve Gossett, and Paul A. Craig \\ Middle Tennessee State University \\ ${ }^{1}$ This research was supported by a MTSU Faculty Research Development Grant.
}

\begin{abstract}
General Aviation (GA) pilots working toward their instrument rating in aircraft equipped with Global Positioning System (GPS) technology often receive little, if any, formal flight instruction on the use of GPS technology. The goal of this study was to empirically evaluate a single pilot crew, FAA Industry Training Standards (FITS) scenario-based training program designed to increase the knowledge and safety of pilots using this technology by focusing on GPS mode awareness, situational assessment, risk and time management, and situational awareness. This study included forty-six pilots who had completed their instrument rating in a GPSequipped aircraft within the last 12 months. The results of this study revealed that utilizing a GPS FITS scenariobased training program for GPS training significantly reduced omission errors and incorrect or inappropriate use of the GPS when compared to controls. These results support the premise that a specific GPS FITS-based training course be required for pilots unfamiliar with GPS navigation, and those pilots should be required to obtain a logbook endorsement before acting as pilot in command of aircraft with IFR-approved GPS units.
\end{abstract}

\section{INTRODUCTION}

Despite the many advantages of increased flight deck automation (Amalberti, 1998; Fanjoy \& Young, 2005; Funk et al., 1997), automated flight decks are now placing cognitive demands on crews that have never before been experienced. As a result, some researchers and aviation experts argue that more, rather than fewer errors, are being observed (Funk, Lyall, \& Niemczyk, 1997; Parasuraman \& Riley, 1997; Roessingh et al., 1998). Many automation human factors issues have recently been raised (Billings, 1997; Fanjoy \& Young, 2005). Two of the most common problems being observed in the modern flight deck are "lack of mode awareness" and "loss of situational awareness" (Nikolic \& Sarter, 2000; Sarter \& Woods, 1995). Lack of mode awareness results from a situation where flight crews are confused about the status of the automation after the aircraft performs a flight maneuver that was not anticipated by the crew (Endsley \& Kaber, 1999). Lack of situational awareness is when a flight crew is not precisely sure of where they are, and often occurs when a flight crew is overly dependent on the navigational moving map displays that are characteristic of automated flight decks (Uhlarik, Raddatz, \& Elgin, 2002; Funk et al.,
1997). This lack of mode awareness, when accompanied by a lack of situational awareness, has led to several controlled flight into terrain (CFIT) accidents. CFIT accidents occur when an aircraft strikes the ground under controlled conditions or in a near wings level attitude without the crew being aware of the impending disaster. One infamous example occurred on December 20, 1995, when American Airlines flight 965, a Boeing 757, crashed into mountainous terrain while on an approach into Cali, Colombia killing 152 passengers and 8 crew (Aeronautica Civil of the Republic of Colombia, 1996). Less than one year after the Cali tragedy, on August 6 1997, Korean Air flight 801, a Boeing 747, crashed with 254 people on board including 2 pilots, one flight engineer, and 14 flight attendants. The airplane had been cleared to land on runway 6 Left when it struck high terrain only 3 miles southwest of the airport at Nimitz Hill, Guam. Of those on board, 228 were killed (NTSB, 2000). In both cases, it was concluded that lack of mode awareness was a contributing factor (Aeronautica Civil of the Republic of Colombia, 1996; NTSB, 2000).

One critical component of any automated cockpit is its flight navigation system (Wiener, 1988). One of the most popular in the General 
Aviation (GA) community is the Global Positioning System, commonly referred to as GPS. GPS is a satellite-based navigation system made up of a network of 24 satellites placed into orbit by the U.S. Department of Defense. The satellites continuously broadcast signals that are received by GPS units that are either "handheld" portable devices, or permanently installed in an aircraft. Navigational signals transmitted by the satellites are then received by these GPS units and this information is used to calculate the aircraft's exact location. It is estimated that as many as two thirds of GA pilots in the United States use some form of GPS technology as their primary means of navigation (Casner, 2002; Casner, 2005). While GPS moving map displays should increase situational awareness in pilots, several recent studies have reported that the lack of thorough knowledge of GPS functionality and dependability has actually lead to a loss of situational awareness in GA pilots (Adam, Deaton, Hansrole, \& Shaikh, 2004; Casner, 2005).

Currently, in the GA community, there is no accepted training program for pilots flying aircraft equipped with GPS technology. This has led to a kind of "self-instruction" where GA pilots either teach themselves to use their GPS or obtain informal instruction from other GPS users. While in some cases this has resulted in relatively minor problems, for example, penetrating a restricted airspace, in other cases, the results have been more tragic (O'Hare \& St George, 1994). Consequently, one key issue with the establishment of GPS technology in GA aircraft is how to train pilots/students to take advantage of the increased safety opportunities available with the new technology. It can be argued that a thorough training program is needed to educate pilots on the use of GPS technology. Indeed, in a recent study on GPS usability (Adam et al., 2004) it was recommended that a specific GPS training program be compared to a control group not receiving any formal GPS training. If successful, the training program could be submitted to the FAA for incorporation in flight schools (Adam et al., 2004). While there is a substantial literature base supporting the notion that a training program on a specific task will increase a learner's proficiency of that task (Schwartz,
Wasserman, \& Robbins, 2001), the authors are unaware of any empirical data that currently exists to support the claim that a GPS training program will increase pilot proficiency in the use of GPS technology. Moreover, what constitutes a viable training program is also unknown.

In 2001, the FAA implemented the FAAIndustry Training Standards (FITS) program. The FITS training program uses highly structured "scripts" of flight training objectives using "real-world" objectives in order to increase safety in increasingly complicated (automated) aircraft. This training places a major emphasis on: aeronautical decision making skills, risk management, situational awareness, and single pilot resource management using real-time flight scenarios (Ayers, 2006; Glista, 2003). Studies from Embry-Riddle Aeronautical University, the University of North Dakota, and Middle Tennessee State University on the effectiveness of the FITS curriculum have resulted in the FAA accepting the FITS training approach as the industry standard for all future flight training in GA (Ayers, 2006; Craig, Bertrand, Dornan, Gossett, \& Thorsby, 2005a, 2005b; Dornan, Craig, Gossett, \& Beckman, 2006; Glista, 2003). In this study, a FITS training program focusing on GPS navigation using real flight scenarios in a computer-based GPS training (CBT) program was utilized. The results of the group of pilots trained in this manner were compared to two groups of pilots which did not receive a GPS FITS training program.

\section{METHODOLOGY}

This study was comprised of forty-six college student pilots who had completed their instrument rating in a GPS-equipped aircraft within the last 12 months. All participants completed two written pre-screening tests. The first was a 25 question test to evaluate their overall GPS knowledge, while the second was a 50 question test to assess their specific knowledge of the Garmin 430 system. In addition, all participants were administered a questionnaire regarding demographics and flight experience. Before the beginning of the training experiment, each participant was given a 
familiarization session in a Middle Tennessee State University Frasca 142 flight training device. While this device is equipped with a panel-mounted, IFR-approved, Garmin 430 GPS, the point of this session was solely to expose each participant to flight in this particular FTD, not to measure the participant's ability to operate the GPS. During this familiarization session, pilots were instructed to fly an instrument approach into Nashville International Airport without using the GPS. After the familiarization session, participants were randomly assigned to one of three groups: 1) FITS-GPS based training, 2) IFR Control or 3), Self-Instruction Control. Each participant was then evaluated on an IFR flight scenario that was designed to assess their aircraft monitoring skills (situational assessment), GPS mode awareness, situational awareness, and understanding of the appropriate Garmin 430 IFR programming. The flight scenario lasted approximately 60 minutes. After this initial evaluation flight, each group received different training.

The FITS-GPS group received four, two hour training sessions using scenarios based on a FITS training syllabus and concentrating on SRM, mode awareness, situational awareness, time management, and situational assessment (situational assessment stresses the importance of flight parameter monitoring, e.g. engines systems airspeed, while flying an automated aircraft). This training was conducted using PCbased computer based training (CBT) utilizing a Garmin 430 simulation software program. In addition, the FITS "Personal and Weather Risk Assessment Guide” was also incorporated into the training program for this group. The "Personal and Weather Risk Assessment Guide" is designed to assist pilots in developing their own personal weather minimums, using Aeronautical Decision Making as a key element in the decision making process. The following is an example of what was included in the FITSGPS group training sessions: 1) Overview of Automation Issues (e.g. mode awareness, automation traps), 2) Situational Awareness: An overview of techniques to enhance situational awareness, 3) An Overview of General Principles of GPS technology, 4) Specific Garmin 430 programming skills, 5) PC-Based CBT using FITS training principles, 6) Critical thinking skills using NTSB reports of fatal aircraft accidents that were automation induced, and 7) The importance of using the "Personal and Weather Risk Assessment Guide" when making Go/No Go decisions. Since the FITSGPS group was provided four training sessions, for a total of eight hours with an instructor, to reduce the likelihood of experiencing a treatment effect, a similar amount of training exposure was given to the IFR control group. This group of participants, received four, two hour training sessions. These sessions, however, only covered basic IFR flying skills, and were designed as essentially an IFR refresher course.

Since one of our earlier premises about GPS training is that the majority of pilots learn via "self instruction" where they basically read the GPS manual supplied by the manufacturer, a third group of participants was included in the study. This group called the "Self-Instruction" group, was each given a copy of the Garmin 430 manual after their initial GPS evaluation flight, and was instructed to read the manual and become familiar with the Garmin 430 before the final GPS evaluation flight. Following the various training sessions or self study, all three groups were evaluated on their performance on another flight scenario in the Frasca 142 FTD. During both their initial and final flight sessions, incorrect or correct GPS mode usage was recorded. A "GPS error" was recorded for the following pilot actions: 1) An air traffic control (ATC) clearance was given requiring GPS programming, but the programming was not performed by the pilot. 2) An ATC clearance was given requiring GPS programming, but the GPS was used inappropriately, 3) An ATC clearance was given requiring GPS programming and the pilot used appropriate GPS programming, but failed to comply with an ATC instruction (e.g. the pilot was too busy programming the GPS and so forgot to level off at an assigned altitude). No errors were recorded if a pilot followed an ATC clearance accurately and used appropriate GPS programming. For example, in one instance an ATC clearance was given which instructed the pilot to cross a particular fix at a specific altitude. No error was recorded if the pilot used the "VNAV/VSR" on the GPS (an appropriate GPS mode). If the pilot began to descend immediately, however, without 
usting the GPS at all, then an error was recorded. A total of 12 ATC clearances requiring Specific EPSS programming were given during both the initial and firol flight scenarios. Following the completion of the study, the total ${ }_{-}$number of
GPS errors from each flight were analyzed using an analysis of variance (ANOVA) 2 X 3 mixed design. Any significant main effects were assessed by post hoc analysis using the Scheffe's test.

Table 1. Overview of Study Groups

\begin{tabular}{|c|c|c|c|c|}
\hline Group & $\begin{array}{l}\text { MEAN } \\
\text { "AGE }\end{array}$ & $\begin{array}{l}\text { MEA ÁN TOTAL } \\
\text { TIME }\end{array}$ & $\begin{array}{l}\text { MEAN TOTAL } \\
\text { INSTRUMENT }\end{array}$ & $\begin{array}{l}\text { MEAN TOTAL } \\
\text { ACTUAL }\end{array}$ \\
\hline \multicolumn{2}{|c|}{ G̊PS-FITSgore Training } & \multirow{2}{*}{$\begin{array}{l}\text { After Training } \\
181.6\end{array}$} & & \\
\hline $\begin{array}{l}\text { Training } \\
(\mathrm{n}=17)\end{array}$ & 20 & & 43.1 & 4.2 \\
\hline $\begin{array}{l}\text { IFR Training } \\
(n=19)\end{array}$ & 21 & 220.3 & 42.7 & 2.3 \\
\hline $\begin{array}{l}\text { Self } \\
\text { Instruction } \\
(n=10)\end{array}$ & 20 & 195.7 & 44.6 & 5.1 \\
\hline
\end{tabular}

\section{RESULTS}

As can be seen in Table 1, a multivariate comparison of group means of total flight time, total instrument time, and total actual instrument time, revealed non-significant differences between the three groups utilized in the study ( $p$ $>0.05$ ). Figures 1 and 2 depict the results of the participants on the written overall GPS knowledge test (Figure 1), and the specific Garmin 430 knowledge test (Figure 2), of all three groups both before and after the training program. As can be seen from these figures, before training all participants experienced a high number of errors on both the overall GPS knowledge test and the specific Garmin 430 knowledge test. Following the use of the FITS training program on GPS and Garmin 430 procedures, however, a significant decrease in errors on both overall GPS (Figure 1) and Garmin 430 (Figure 2) knowledge was observed as compared to both control groups.

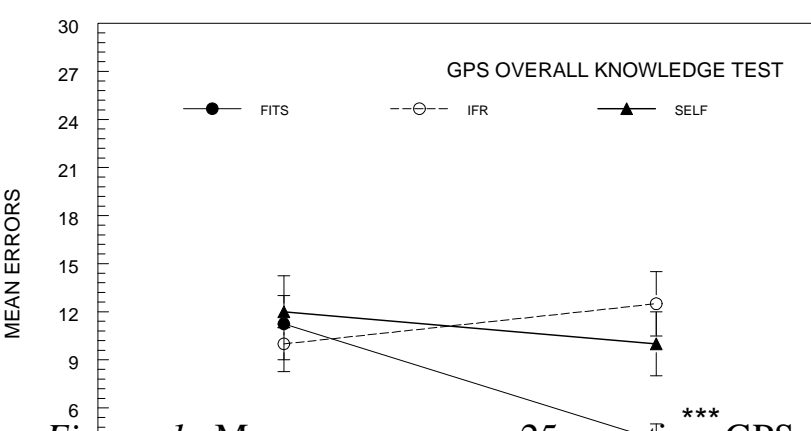

Figure 1. Mean errors on a 25 question GPS overall knowledge test in the FITS GPS trained group comporedainto the control groupssanbefore, and after a specific training program (see text for specific details). $* * *=$ significantly different from all other groups $(\mathrm{p}<0.01)$. 
can be seen from Figure 3, however, the FITS trained group had significantly fewer errors when compared to both groups.

\section{DISCUSSION}

Figure 2. Mean errors on a 50 question Garmin 430 knowledge test in the FITS GPS trained group compared to the control groups before, and after a specific training program (see text for specific details). ${ }^{* * *}=$ significantly different from all other groups ( $\mathrm{p}<0.01)$.

This was revealed by a significant group by treatment interaction for overall GPS knowledge $(\mathrm{F}(2,85)=7.5, \mathrm{p}<0.001)$, and specific Garmin 430 knowledge $(\mathrm{F}(2,86)=5.6, \mathrm{p}<0.005)$. Post hoc comparison revealed that both the Self Instruction control group and the FITS-GPS group improved in their Garmin 430 knowledge compared to the IFR control group. Further post hoc analysis revealed that the FITS-GPS group was significantly different from all other groups on both tests.

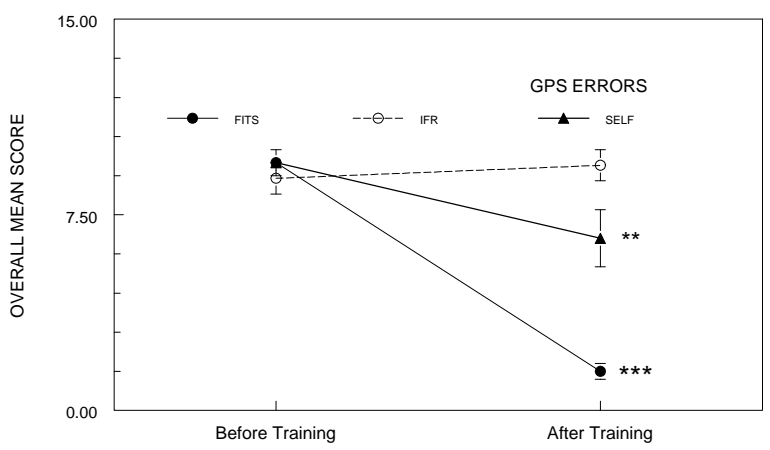

Figure 3. GPS mean errors in the FITS GPS scenario-based training group compared to controls on two simulator flight scenarios. $* * *=$ significantly different from all groups, $(\mathrm{p}<$ $0.01) ; * *=$ significantly different from the IFR and FITS group, $(\mathrm{p}<0.01)$.

Figure 3 illustrates GPS competency scores in the three groups before and after training. An ANOVA revealed a significant group by treatment interaction $(\mathrm{F}(2,86)=29.6, \mathrm{p}<$ 0.001 ). Post hoc analysis again revealed that both the FITS GPS training program pilots and the self taught pilots made significantly fewer errors compared to the IFR control group. As
The results of this study revealed that prior to undertaking a training program focusing on GPS technology, GPS flight planning, mode awareness, and situational awareness, pilots who had recently obtained their instrument rating in a panel mounted, IFR-approved GPS aircraft in reality knew very little about appropriate GPS procedures. This was demonstrated first by participants' poor scores on the initial written tests evaluating both general GPS and Garmin 430 specific knowledge. Very few subjects displayed in-depth knowledge of GPS technology, or a commanding knowledge of the Garmin 430. For example, fewer than ten percent of the pilots were able to choose the correct answer to the following multiple choice question: "When using the approach page on the Garmin 430, if the "VOR 03" approach is highlighted and "GPS" is in italics beside the "VOR 03", what does this mean?"

Secondly, participants did not demonstrate an acceptable level of operational GPS knowledge when evaluated in the baseline flight scenario ("Before Training", Figure 3) Indeed, in the initial flight evaluation scenario that occurred before the training sessions, all participants displayed a significant amount of inappropriate GPS programming, omission errors (when the GPS was not used following an ATC clearance), poor time management, and lack of mode awareness. This lack of GPS awareness resulted in a significant amount of time spent pre-occupied with the GPS, which resulted in a lack of situational awareness (many participants were completely disoriented and, as a result, often dangerously off course). Situational assessment suffered as well, this is where a pilot spends a significant amount of time focusing on his/her automation and considerably less time monitoring the flight instrument/engine panel. For example, in many cases, the focus on the GPS display resulted in altitude busts or overshooting an assigned 
heading; or, in other situations, not noticing a precipitous increase in oil temperature.

The lack of GPS knowledge that was observed at the beginning of this study was in striking contrast to pilots' self-reported comfort levels with a GPS equipped aircraft. Before the study began, 93 percent of pilots reported feeling "comfortable" using a GPS in the IFR environment, while 83 percent felt "comfortable" shooting a GPS approach (data not shown). The results of the baseline data gathered for this study strongly suggest that the traditional GPS training given to instrument rating applicants is insufficient, given the dramatic changes in technology that now typify GA aircraft. Since the traditional IFR training curriculum focuses on rote learning, this method is arguably antiquated and must be changed to prepare pilots to handle the technology with which their aircraft is equipped. For example, more emphasis should be placed in the current Part 141 instrument syllabus on GPS mode awareness and proper time management skills. Instead, the focus is on learning how to fly GPS approaches, and this is accomplished by executing multiple practice approaches. While the ability to fly a GPS approach correctly is certainly a requirement for effectively operating a GPS-equipped aircraft, there is much more that needs to be learned to safely operate a GPSequipped aircraft in the IFR environment.

In this study, the experimental group which received four CBT seminars using the FITS training approach, demonstrated significantly better scores on both the post-training general GPS assessment test and the Garmin 430 assessment test than did either control group. Even more importantly, this group committed fewer errors on the post-training evaluation scenario, compared to either the IFR or Self instruction groups. These results suggest that a training intervention is a positive factor in enhancing a pilot's ability to appropriately utilize a GPS.

It is important to note that one control group, which was assigned to "self-instruction" utilizing the Garmin 430 manual, also showed significant improvement in all areas at postassessment, although not as much as the FITSGPS group. Therefore, it can be argued that while self-instruction is beneficial, it is not as effective as a formal GPS training program. A possible explanation for the improvement in the "self instruction" group was that after experiencing poor performance on both the written assessments and the initial flight scenario, that they were motivated to increase their knowledge of GPS procedures. This explanation, however, does not account for the lack of improvement in the IFR group, who experienced similar performance deficits on the initial scenario flight.

Given the stronger post-training performance of the group which received the FITS GPS scenario-based training using a CBT, it seems to follow that all curricula which utilize aircraft with GPS technology should incorporate at least two components. First, ground school should focus on both general GPS technology considerations and on specific GPS knowledge regarding the equipment available in the training aircraft. This training should be followed by specific tests to assess the students' knowledge. Second, GPS ground training should incorporate realistic, GPS scenario-based training using the FITS approach in a CBT program for the specific GPS installed in the aircraft. The use of CBT provides the advantage of enabling both the instructor and the student to focus on such critical tasks as time management, proper mode awareness, and situational awareness. Finally, while not a part of this study, it seems only logical that some minimum number of flight training hours be dedicated for either simulator or flight training immediately following the CBT training. These training hours should also be FITS-based so further real-life scenarios could be experienced. The focus would be on incorporating system management, mode awareness, and situational assessment while actually flying the aircraft. While at first glance this level of training may appear to be overwhelming, all of the training that was done in this study could conceivably be completed over a weekend. The total FITS ground training using a CBT approach was four two-hour sessions. This ground training could then be followed by simulator or aircraft training on the following day.

In conclusion, the results of this study revealed that utilizing a FITS scenario-based GPS training program in a CBT significantly 
improved subject performance on both GPS knowledge tests and on a flight test measuring appropriate use of a GPS when compared to both an IFR control group and a Self-instruction group. However, it must be pointed out that these pilots were ALL college students. Nonetheless, we would argue that these results are still applicable to the general pilot population. Our results further suggest that, given the lack of initial GPS knowledge that seemed to be prevalent in our sample, a specific logbook endorsement should be required of pilots who wish to fly under IFR in a GPSequipped aircraft. Lastly, anyone interested in obtaining this training program should contact the first author. 


\section{REFERENCES}

Adam, H., Deaton, J. E., Hansrole, R. W., \& Shaikh, M. A. (2004). An analysis of GPS usability and human performance in aviation. International Journal of Applied Aviation Studies, 4, 107-131.

Aeronautica Civil of the Republic of Colombia. (1996). Controlled Flight into Terrain, American Airlines Flight 965, Boeing 757-223, N651AA, Near Cali, Colombia. Santafe de Bogota, DC, Colombia: Aeronautica Civil of the Republic of Colombia.

Amalberti, R. R. (1998). Automation in aviation: A human factors perspective. In D. J. Garland \& J. Wise \& D. Hopkin (Eds.), Aviation Human Factors (pp. 173-192). Hillsdale, NJ: Lawrence Erlbaum Associates.

Ayers, F. H. (2006). The application of scenario based recurrent training to teach single pilot resource management (SRM) under the FAA Industry Training Standards (FITS) Program. Journal of Aviation/Aerospace Education and Research, 3, 13-25.

Billings, C. E. (1997). Aviation automation: The search for a human-centered approach. Mahwah, NJ: Lawrence Erlbaum Press.

Casner, S. M. (2002). Cockpit Automation: For General Aviators and Future Airline Pilots: Iowa State Press.

Casner, S. M. (2005). Transfer of learning between a small technically advanced aircraft and a commercial jet transport simulator. International Journal of Applied Aviation Studies, 5(2), 307-320.

Craig, P. A., Bertrand, J. E., Dornan, W., Gossett, S., \& Thorsby, K. K. (2005a). Ab Initio training in the glass cockpit era: New technology meets new pilots. Paper presented at the International Symposium on Aviation Psychology.

Craig, P. A., Bertrand, J. E., Dornan, W., Gossett, S., \& Thorsby, K. K. (2005b). Scenario-based Private/Instrument syllabus versus traditional maneuver-based syllabi: A preliminary descriptive analysis. Collegiate Aviation Review, 23, 23-27.

Dornan, W. A., Craig, P. A., Gossett, S., \& Beckman, W. A. (2006). Best evidence for the FAA Industry Training Standards program for pilot training in technically advanced aircraft. Collegiate Aviation Review, 24(1), 58-66.

Endsley, M. R., \& Kaber, D. B. (1999). Level of automation effects on performance, situation awareness and workload in a dynamic control task. Ergonomics, 42(3), 462-492.

Fanjoy, R. O., \& Young, J. P. (2005). Flight deck automation: Line pilot insight for improved initial pilot training. International Journal of Applied Aviation Studies, 5(1), 13-23.

Funk, K. H., Lyall, E. A., \& Niemczyk, M. C. (1997). Flightdeck automation problems: Perceptions and reality. In M. Mouloua \& J. M. Koonce (Eds.), Human-automation interaction: Research and practice (pp. 29-34). Mahwah, New Jersey: Lawrence Erlbaum Associates.

Glista, T. (2003, March/April). FAA/Industry Training Standards (FITS): Times (and training requirements) are a changing. FAA Aviation News, 1-4.

National Transportation Safety Board (NTSB). (2000). Controlled Flight into Terrain, Korean Air Flight 801, Boeing 747-300, HL7468, Nimitz Hill, Guam, August 6, 1997 (Aircraft Accident Report NTSB/AAR-00/01). Washington, DC: National Transportation Safety Board.

Nikolic, M. I., \& Sarter, N. B. (2000). Peripheral visual feedback: A powerful means of supporting attention allocation and human-automation coordination in highly dynamic data-rich environments. Human Factors, 43(1), 30-38. 
O'Hare, D., \& St George, R. (1994). GPS- (Pre) cautionary tales. Airways, 6, 12-15.

Parasuraman, R., \& Riley, V. (1997). Human and automation: Use, misuse, disuse, abuse. Human Factors, 39(2), 230-253.

Roessingh, J. J. M., Van Gent, R. N. H. W., Fletcher, G., Dudfield, H., Lodge, M., Koehl, F., Linsenmaier, B., \& Erismann, J. F. (1998). European Collaboration on Transition Training Research for Improved Safety (ECOTTRIS) - Final report: European Commission on Transport (DG VII).

Sarter, N., \& Woods, D. D. (1995). How in the world did we ever get into that mode? Human Factors, 37, 5-19.

Schwartz, B., Wasserman, E. A., \& Robbins, S. J. (2001). Psychology of Learning and Behavior (5 ${ }^{\text {th }}$ Ed.). New York: W. W. Norton \& Company.

Uhlarik, J., Raddatz, K. R., \& Elgin, P. D. (2002). Cockpit display of weather and operational information: Identification of human issues: Part 2: Human factors issues and certification guidelines. Washington, DC: Federal Aviation Administration.

Wiener, E. L. (1988). Cockpit automation. In E. L. Weiner \& D. C. Nagel (Eds.), Human Factors in Aviation (pp. 433-461). San Diego: Academic Press. 